Article

\title{
Controllable Drug Release Behavior of Polylactic Acid (PLA) Surgical Suture Coating with Ciprofloxacin (CPFX)_Polycaprolactone (PCL)/ Polyglycolide (PGA)
}

\author{
Shuqiang Liu 1,2,*,+ Juanjuan Yu 1,+, Huimin Li ${ }^{1}$, Kaiwen Wang ${ }^{1}$, Gaihong Wu 1,*, \\ Bowen Wang ${ }^{1}$, Mingfang Liu ${ }^{1}$, Yao Zhang ${ }^{1}$, Peng Wang ${ }^{1}$, Jie Zhang ${ }^{1}$, Jie Wu ${ }^{1}$, Yifan Jing ${ }^{1}$, \\ Fu Li ${ }^{1,2}$ and Man Zhang ${ }^{1,2}$ \\ 1 College of Textile Engineering, Taiyuan University of Technology, Taiyuan 030024, China; \\ yuxiaoyuy@126.com (J.Y.); wo1553557384@163.com (H.L.); wkw1011@163.com (K.W.); \\ wangbowen316@163.com (B.W.); lmf118119@163.com (M.L.); zy32164872@126.com (Y.Z.); \\ tyut19834520797@163.com (P.W.); Zj13283543186@163.com (J.Z.); 18234506489@163.com (J.W.); \\ mary1123@126.com (Y.J.); lifu@tyut.edu.cn (F.L.); zhangman@tyut.edu.cn (M.Z.) \\ 2 Biomedical Textile Laboratory, Taiyuan University of Technology, Jinzhong 030600, China \\ * Correspondence: liushuqiang8866@126.com (S.L.); gaigai2003@126.com (G.W.) \\ + These authors contributed equally to this work and should be considered co-first authors.
}

Received: 24 December 2019; Accepted: 30 January 2020; Published: 1 February 2020

\begin{abstract}
Polylactic acid (PLA) surgical suture can be absorbed by human body. In order to avoid surgical site infections (SSIs), the drug is usually loaded on the PLA suture, and then the drug can release directly to the wound. Because the different types of wounds heal at different times, it is needed to control the drug release rate of PLA suture to consistent to the wound healing time. Two biopolymers, polyglycolide (PGA) and polycaprolactone (PCL), were selected as the carrier of ciprofloxacin (CPFX) drug, and then the CPFX-PCL/PGA was coated on the PLA suture. The degradation rate of drug-carrier can be controlled by adjusting the proportion of PCL/PGA, which can regulate the rate of CPFX drug release from PLA suture. The results show that the surface of PLA suture, coating with PCL/PGA, was very rough, which led to increased stitching resistance when we were suturing the wound. These materials, such as the PLA suture, the PCL/PGA carriers and the CPFX drug, were just physically mixed rather than chemically reacted, which was very useful for ensuring the original efficacy of CPFX drug. With the increasing of PCL in the carriers, both the breaking strength and elongation of these un-degraded sutures increased. During degradation, the breaking strength of all sutures gradually decreased, and the more PCL in the coating materials, the longer effective strength-time for the suture. With the increasing of PCL in the drug-carrier, the rate of drug releasing became lower. The drug release mechanism of CPFX-PCL/PGA was a synergistic effect of drug diffusion and PCL/PGA carrier dissolution.
\end{abstract}

Keywords: polylactic acid suture; ciprofloxacin; polyglycolide; polycaprolactone; drug release

\section{Introduction}

Polylactic acid (PLA) polymer has some good properties, such as biocompatibility, biodegradability, non-toxicity and high strength, so it is usually used as the biomedical and pharmaceutical material [1-3]. PLA has a good compatibility with human tissues, and can be gradually degraded into safe products of $\mathrm{CO}_{2}$ and $\mathrm{H}_{2} \mathrm{O}$ in vivo. Moreover, the intermediate product of PLA is lactic acid (LA), which is the normal sugar metabolite and does not accumulate in human's vital organs. Therefore, the filaments, which are made of PLA, can be used as the suture which can be absorbed by human body [4-6]. 
The PLA surgical suture has been widely used in the medical field, but there is a problem of postoperative infection. The reduction of surgical site infections (SSIs) promises to be an area of intense interest and activity in the foreseeable future [7-9]. In order to avoid SSIs, it is a common method to take a large number of drugs by injection or orally. However, those drugs, which are applied throughout the body, have some great side-effects on human's tissues and organs. Therefore, it is a straightforward and effective method to load the drugs on the PLA suture, which can release the drug directly to the wound [10-12].

In the medical field, there is a requirement for the drug release of drug-loaded surgical suture. Because the different types of wounds would heal at different times, the release time of drug from surgical suture should be consistent or close to the wound healing time. If the drug release time of suture is much longer than the wound healing time, this will be equivalent to overdose, which will cause some toxic and side effects on the tissues. If the drug release time of suture is much shorter than the wound healing time, the drugs will not play a role in the treatment of wound. Therefore, it is need to control the drug release time of surgical suture, so as to be consistent with the different healing time of wounds.

Currently, some experts have used different methods to load drug onto the surgical suture. Champeau et al. [13] studied the relationship between three implant polymer sutures and two anti-inflammatory drugs under supercritical $\mathrm{CO}_{2}$. They used a simple dipping method to load the drug onto the suture, and focused on the effect of experimental conditions on drug-loading, rather than how to control the drug release. Lee et al. [14] demonstrated that the drug of dexamethasone can be attached to the lactide suture in the form of microspheres. This suture has an anti-inflammatory effect, but does not control the release of drug. Weldon et al. [15] reported a method for placing the drug of aspirin into PLA/RSF nano-fibers by electro-spinning, but this method is still unable to control the drug release. In conclusion, these drug-loading methods, applied in the previous research results, are not yet able to control the rate and cycle of drug release from suture.

In order to control the rate and cycle of drug release from PLA suture, we applied a new method of drug delivery in this paper, as shown in Figure 1. Two biopolymers, polyglycolide (PGA) and polycaprolactone (PCL), are selected as the carrier of drug in this paper. The biopolymers of PGA and PCL are mixed with the drug to make a mixed liquid. Then the mixed liquid is coated onto the surface of PLA suture by dip rolling process. Finally, the PLA suture coating with PGA, PCL and the drug are prepared.

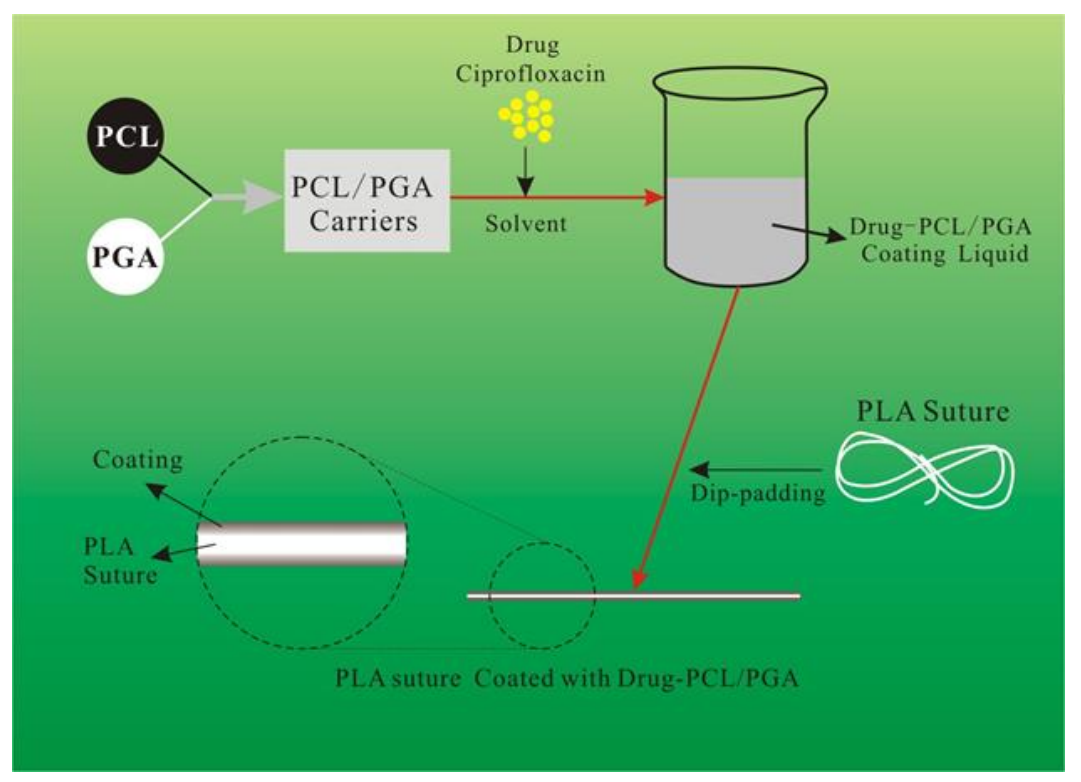

Figure 1. The whole scheme in this paper. 
It should be noted that the biopolymers of PGA and PCL, which are the carrier of drug and coated on the suture, have different degradation rate. The degradation rate of PGA is higher than that of PCL [16-18]. We can control the degradation rate of drug-carrier by adjusting the proportion of PGA and PCL. As the drug-carrier of PGA/PCL degrades, the internal drugs are released. Therefore, the proportion of PGA and PCL is an important factor to regulate the rate and cycle of drug release from suture. In addition, the drug coated on the suture is Ciprofloxacin (CPFX), which has a strong antibacterial effect against gram-positive bacteria by inhibiting the gyrase of one of the bacterial DNA synthetase enzymes [19-21].

In this paper, the tensile properties of sutures with different ratio of PCL/PGA were measured and the chemical structure of coating was characterized. In the process of degradation and drug release, the surface morphology of the sutures were observed, the time of the suture strength failure, the release rate and cycle of the drug were recorded, and the release kinetics model was established. Besides the mechanism of drug release by sutures were analyzed. We conducted these investigations to provide a theoretical basis for the development of drug-loaded PLA surgical sutures with excellent controlled-release properties, small side effects, and safe and reliable clinical application.

\section{Materials and Methods}

\subsection{Materials}

The original PLA surgical suture, with 33.72 tex, breaking strength: $32.51 \mathrm{cN} /$ tex, elongation at break: $28.48 \%$, was produced by Zhejiang Gaoxin Company (Jiaxing, China).

The drug carrier was made from PGA $\left(\left(\mathrm{C}_{4} \mathrm{H}_{4} \mathrm{O}_{4}\right)_{\mathrm{n}}, M_{\mathrm{W}}=11,602 \mathrm{~g} / \mathrm{mol}\right)$ and PCL $\left(\left(\mathrm{C}_{6} \mathrm{H}_{10} \mathrm{O}_{2}\right)_{\mathrm{n}}\right.$, $M_{\mathrm{w}}=50,000 \mathrm{~g} / \mathrm{mol}$ ), which were supplied by Natureworks Company (Blair, NE, USA).

The drug used in this paper is $\mathrm{CPFX}\left(\mathrm{C}_{17} \mathrm{H}_{18} \mathrm{FN}_{3} \mathrm{O}_{3}\right.$, purity $\left.98 \%\right)$, which was purchased from North China biotechnology Co., Ltd., (Zhengzhou, China). CPFX is a new quinolone broad-spectrum antimicrobial agent, which has bactericidal effect on gram-positive and negative bacteria including pseudomonas aeruginosa, intestinal bacteria and staphylococcus aureus. In this paper, CPFX was loaded onto the suture to prevent wound inflammation.

Some chemical reagents were applied in this experiment frequently. For instance, ethyl acetate $\left(\mathrm{CH}_{3} \mathrm{COOC}_{2} \mathrm{H}_{5}\right.$, purity $\left.99.8 \%\right)$, absolute ethyl alcohol $\left(\mathrm{C}_{2} \mathrm{H}_{6} \mathrm{O}\right.$, purity $\left.99.5 \%\right)$, medical alcohol $\left(\mathrm{C}_{2} \mathrm{H}_{6} \mathrm{O}\right.$, purity $75 \%)$, Tween-80 $\left(\mathrm{C}_{2} \mathrm{H}_{44} \mathrm{O}_{6}\left(\mathrm{C}_{2} \mathrm{H}_{4} \mathrm{O}\right)\right.$ n, purity $\left.99 \%\right)$ and Propanetriol $\left(\mathrm{CH}_{2} \mathrm{OHCHOHCH}_{2} \mathrm{OH}\right.$, purity $99 \%$ ) were provided by Yongda Chemical Reagent Company (Tianjin, China). Ferrous tartrate solution $\left(\mathrm{C}_{4} \mathrm{H}_{4} \mathrm{FeO}_{6}\right)$ was obtained from Zhen Jie Quality Inspection Technology Service Company (Guangzhou, China). Phosphate buffer salt (PBS) solution $(\mathrm{pH}=7.4)$ were procured from Sigma Aldrich Company (Shanghai, China).

\subsection{Preparation of Drug-Loaded Suture}

The original PLA surgical sutures should be pretreated firstly. The original PLA sutures were soaked in absolute ethyl alcohol for $2 \mathrm{~h}$ to remove the oil on the surface of suture. After that, the sutures were heat setting in vacuum oven at $60{ }^{\circ} \mathrm{C}$ for $30 \mathrm{~min}$. Then the sutures were impregnated and disinfected in medical alcohol at room temperature for $10 \mathrm{~min}$. Finally, the sutures were dried in the blast oven at $40{ }^{\circ} \mathrm{C}$ for $60 \mathrm{~min}$.

We dissolved $3 \mathrm{~g}$ of PCL and PGA in different proportions in $40 \mathrm{~mL}$ Ethyl Acetate (purity 99.8\%). The carrier solution was prepared by heating and stirring to dissolve PCL and PGA. $1.5 \mathrm{~g}$ of Ciprofloxacin (CPFX) and an emulsifier (Propanetriol, Tween-80) were dissolved in $40 \mathrm{~mL}$ of distilled water to prepare a mixed water solution of drug (CPFX). The water solution of drug (CPFX) was slowly added to the carrier solution of PCL/PGA. The two solutions were fully emulsified, and a drug-coating finishing liquid of CPFX-PCL/PGA was obtained. 
The pretreated PLA surgical suture was treated by the liquid of CPFX-PCL/PGA in the process of dip-padding (Figure 2). After that, the suture was dried in a vacuum oven at $45^{\circ} \mathrm{C}$ for $2 \mathrm{~h}$, and then the PLA suture was coated with CPFX-PCL/PGA.

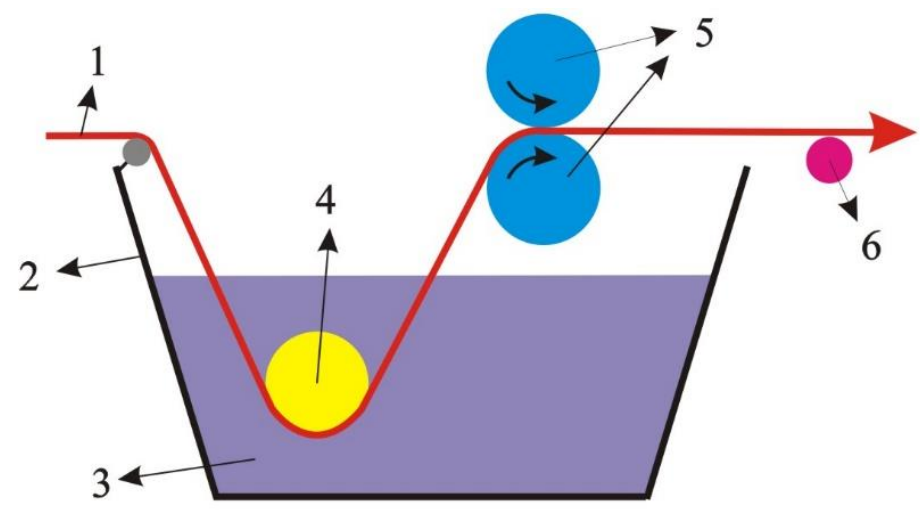

Figure 2. Process of dip-padding. (1) Pretreated polylactic acid (PLA) surgical suture; (2) dip-padding tank; (3) coating finishing liquid of ciprofloxacin (CPFX)-polycaprolactone (PCL)/polyglycolide (PGA); (4) dipping rollers; (5) rubber press rollers; (6) guide roller.

\subsection{Characterization}

The mechanical properties of sutures were tested by electronic single yarn strength tester (YG061FQ, Laizhou Electron Instrument Co., Ltd., Laizhou, China). The clamping length was $250 \mathrm{~mm}$, and the drawing speed was $250 \mathrm{~mm} / \mathrm{min}$.

FTIR spectra of sutures were measured by total reflectance infrared spectroscopy and Fourier infrared spectrometer (Tensor27, Bruker Company, Karlsruhe, Germany). The scanning range was $4000-600 \mathrm{~cm}^{-1}$, resolution $4 \mathrm{~cm}^{-1}$.

The surface morphology of drug-loaded sutures was observed by scanning electron microscopy (JEM2100F, JEOL, Tokyo, Japan) under an acceleration voltage of $10 \mathrm{kV}$. All the samples' surfaces were sputtered with gold.

The degradation and drug-release experiments of sutures were performed in a sterile room, where $12 \mathrm{~h}$ of UV light per day was used to kill bacteria. The coated sutures were placed in a jar which was containing $50 \mathrm{~mL}$ PBS buffer solution. Then the suture was degraded and released drug in vitro by immersing in buffer solution in a constant temperature water bath at $(37 \pm 0.5){ }^{\circ} \mathrm{C}$. After a certain amount of time, the sutures were taken out and dried, and then the surface morphology, strength and other properties of sutures during degradation were measured.

\subsection{Drug Release Behavior In Vitro}

The absorption intensity of ciprofloxacin (CPFX) was measure by an UV-Vis Spectra Photometer (UV-752, Shanghai Yoke Instrument Company, Shanghai, China). The absorbance of CPFX solution with different concentration was determined at $277 \mathrm{~nm}$ wavelength, and $0.1 \mathrm{~mol} / \mathrm{L}$ hydrochloric acid solution was used as blank control. The standard curve can be obtained by using absorbance (y) as vertical coordinate and CPFX concentration $(x)$ as horizontal coordinate, as shown in Figure 3. The linear regression equation of the standard curve obtained in this experiment is $y=1.213 x-0.0007$ $\left(R^{2}=0.997\right)$. 


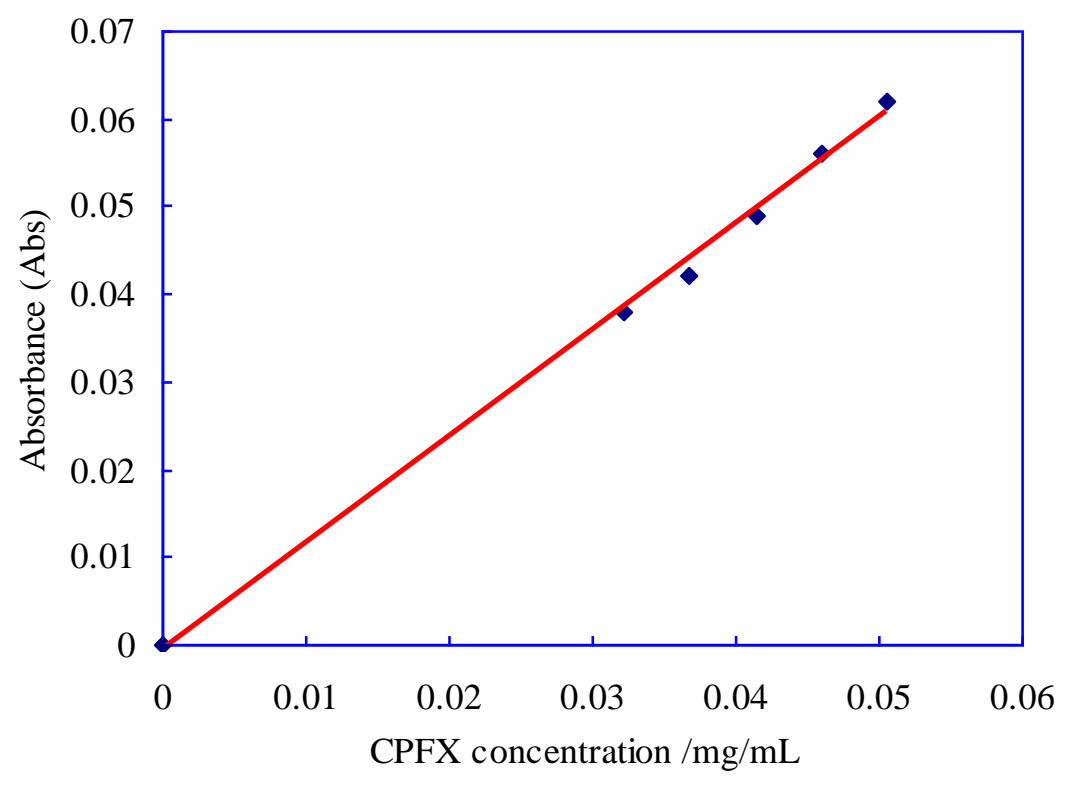

Figure 3. Standard curve of ciprofloxacin (CPFX) drug.

The drug was released during the degradation of the PLA suture. At the predetermined time, $1 \mathrm{~mL}$ of each sample solution was extracted to test the drug content. Meanwhile, an equal amount of fresh buffer was supplemented to each jar [22,23]. The amount of drug release was determined by standard curve of ciprofloxacin and the cumulative release rate was calculated according to Formula (1).

$$
Q_{t}=m_{t} / m_{0} \times 100 \%
$$

where $Q_{t}$ represented the cumulative release rate of ciprofloxacin at $t$ time; $m_{t}$ represented the content of released ciprofloxacin at $t$ time; $m_{0}$ represented the content of ciprofloxacin at initial condition.

\section{Results and Discussion}

\subsection{Surface Morphology of Drug-Loaded PLA Suture}

The surface morphology of the original PLA suture and the PLA suture coating with 50/50 PCL/PGA was observed by SEM, as shown in Figure 4.

It can be seen from Figure 4a that the fibers in original PLA suture, which had no coating, were very loose. In addition, the surface of original PLA suture was very smooth, which led to lower stitching resistance when we were suturing the wound. Figure $4 \mathrm{~b}$ shows that the coating of PCL/PGA wrapped tightly around the fibers, and then the surface of the PLA suture, coating with PCL/PGA, became very rough, which led to increased stitching resistance when we were suturing the wound. Moreover, the fibers in the suture were filled with the coating materials and glued together, which indicated that the coating of PCL/PGA improved the bundling ability of fibers in the suture.

In the process of degradation, the surface morphology of the original PLA suture and the PLA suture coating with 50/50 of PCL/PGA was changed, as shown in Figure 5. 

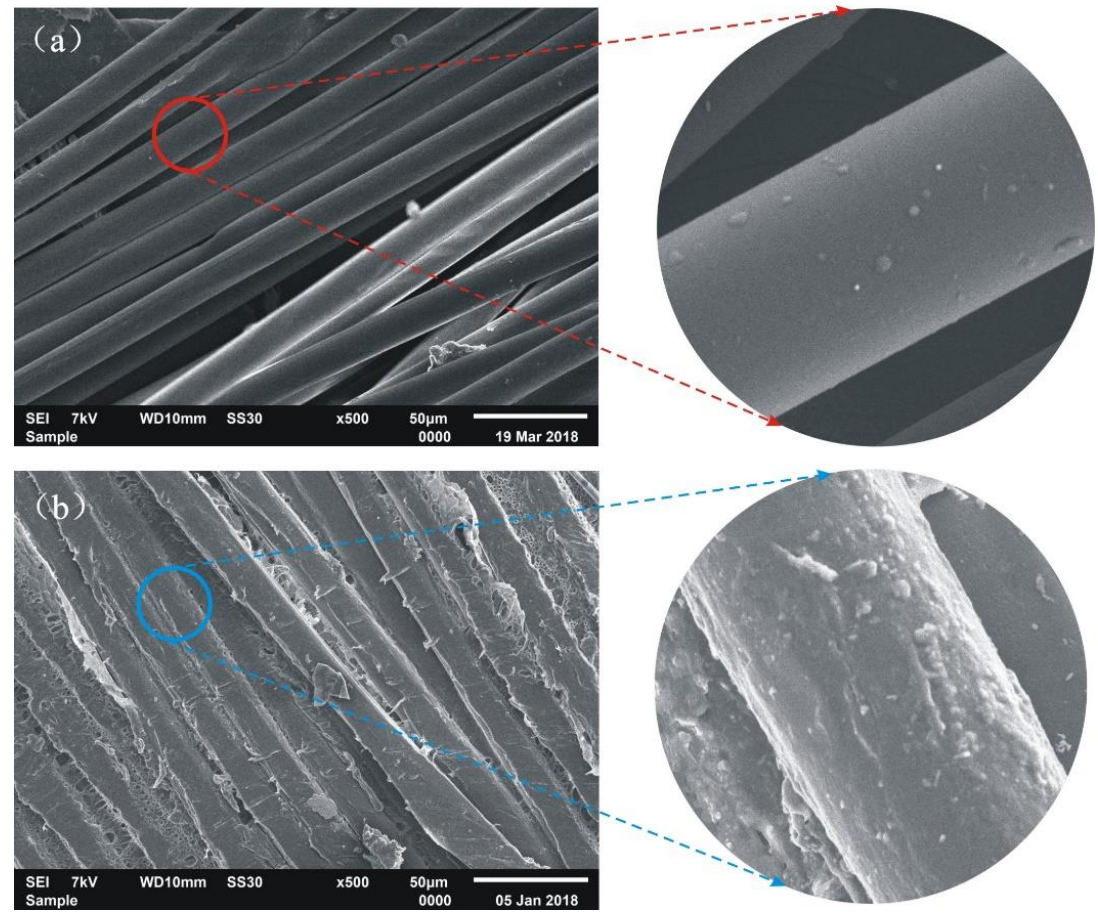

Figure 4. SEM images of suture. (a) Original PLA suture; (b) PLA suture coating with 50/50 of PCL/PGA.

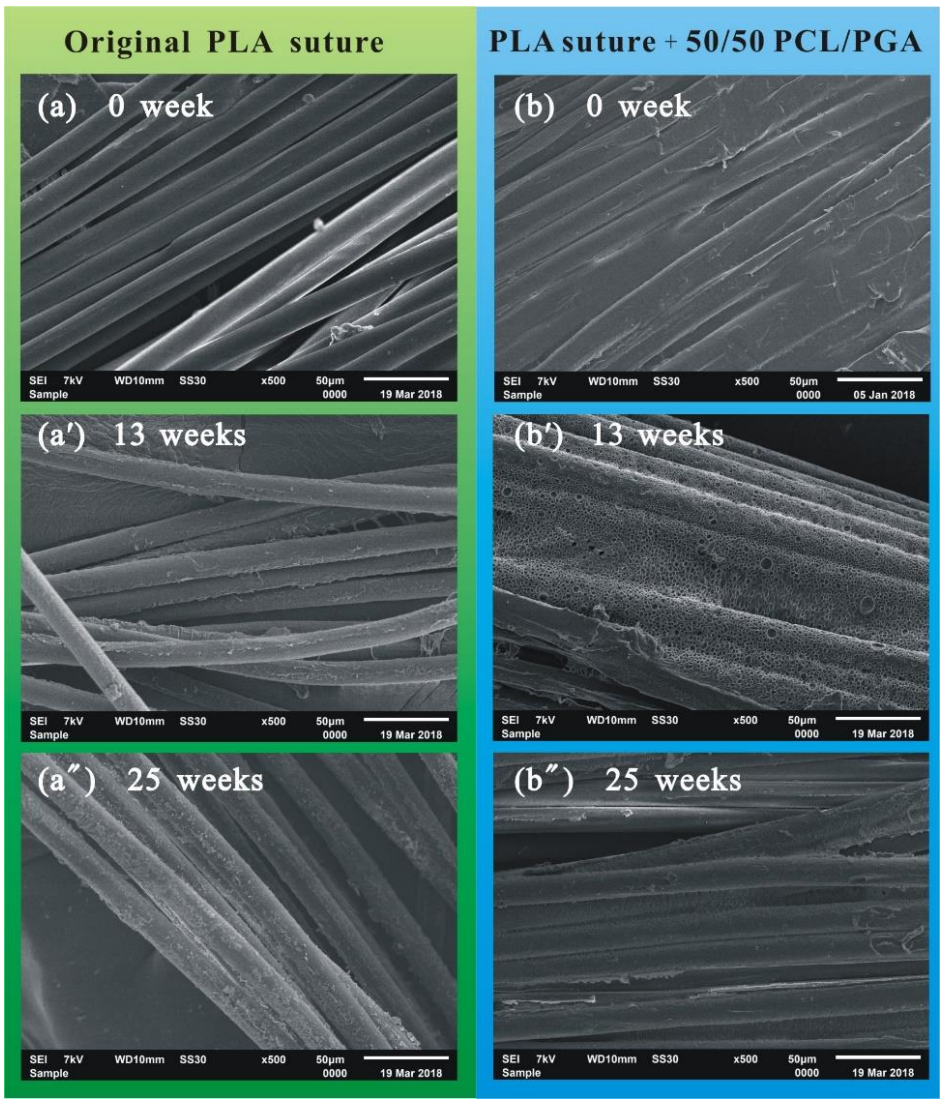

Figure 5. SEM images of sutures. (a) Original PLA suture degraded for 0 week; $\left(\mathbf{a}^{\prime}\right)$ original PLA suture degraded for 13 weeks; (a") Original PLA suture degraded for 25 weeks; (b) PLA suture coating with 50/50 of PCL/PGA degraded for 0 weeks; (b') PLA suture coating with 50/50 of PCL/PGA degraded for 13 weeks; (b") PLA suture coating with 50/50 of PCL/PGA degraded for 25 weeks. 
Figure $5 \mathrm{a}-\mathrm{a}$ " shows that with the extension of degradation process, the surface of the original PLA suture became more and more rough, which indicated that the original PLA suture gradually degraded from the surface of fiber. Figure $5 b-b^{\prime \prime}$ shows that the coating material (PCL/PGA) of the suture was degraded firstly. When degraded for 13 weeks, a large number of holes, as shown in Figure $5 b^{\prime}$, appeared on the coating. When degraded for 25 weeks, as shown in Figure $5 b^{\prime \prime}$, the coating material on the surface of suture was almost completely degraded, and then the internal PLA fibers began to degrade. In short, in the process of degradation, the suture gradually degraded from the coating materials to the inside fibers, and when degraded for about 25 weeks, there was only a small amount of materials degraded on the surface of original PLA suture, but the coating material of PLA suture coating with 50/50 PCL/PGA basically degraded completely.

The coating on the surface of PLA suture can be composed of different proportions of PCL/PGA, such as 70/30 and 30/70. The surface morphologies of PLA suture with different proportions of PCL/PGA were measured during degradation process, as shown in Figure 6.
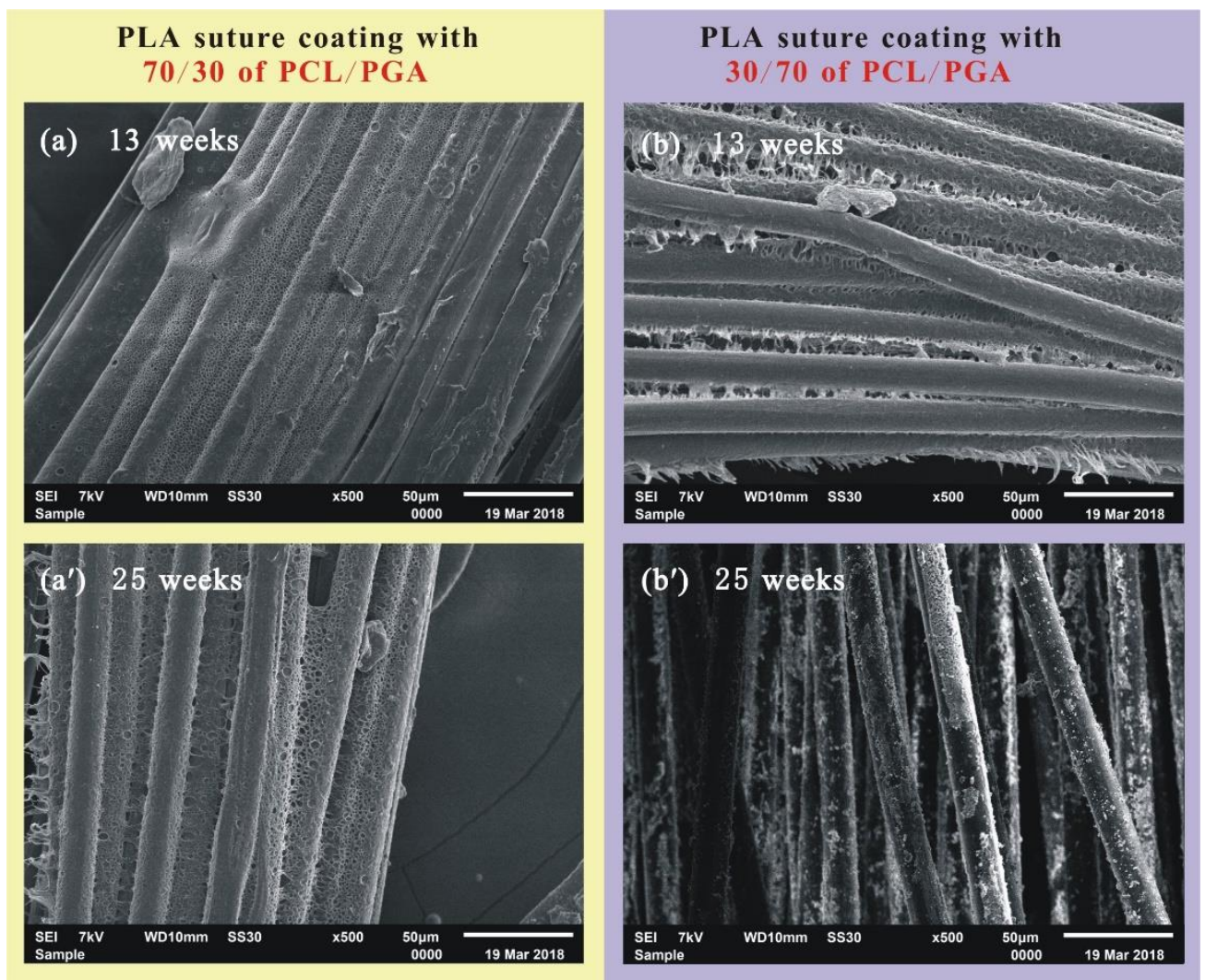

Figure 6. SEM images of suture. (a) PLA suture coating with 70/30 of PCL/PGA degraded for 13 weeks; $\left(\mathbf{a}^{\prime}\right)$ PLA suture coating with 70/30 of PCL/PGA degraded for 25 weeks; (b) PLA suture coating with 30/70 of PCL/PGA degraded for 13 weeks; (b') PLA suture coating with 30/70 of PCL/PGA degraded for 25 weeks.

When the PLA sutures were degraded for 13 weeks (Figure 6a,b), there was more coating materials on the suture with $70 / 30$ of PCL/PGA than that on the suture with 30/70 of PCL/PGA. When degraded for 25 weeks (Figure $6 a^{\prime}, b^{\prime}$ ), there was many coating materials on the suture with 70/30 of PCL/PGA, but the coating materials on the suture, coating with 30/70 of PCL/PGA, was almost completely degraded, and the internal PLA fibers began to degrade. The above phenomena indicate that the surface coating of the suture, coating with 30/70 of PCL/PGA, degraded more quickly than that of the suture, coating with 70/30 of PCL/PGA. This further indicates that the more PCL in the coating, the slower degradation rate of the coating. This is because that the degradation rate of PCL is lower than that of PGA. 


\subsection{Chemical Structure of Drug-Loaded PLA Suture}

The infrared spectra of sutures, coating with different proportions of PCL/PGA, are shown in Figure 7.

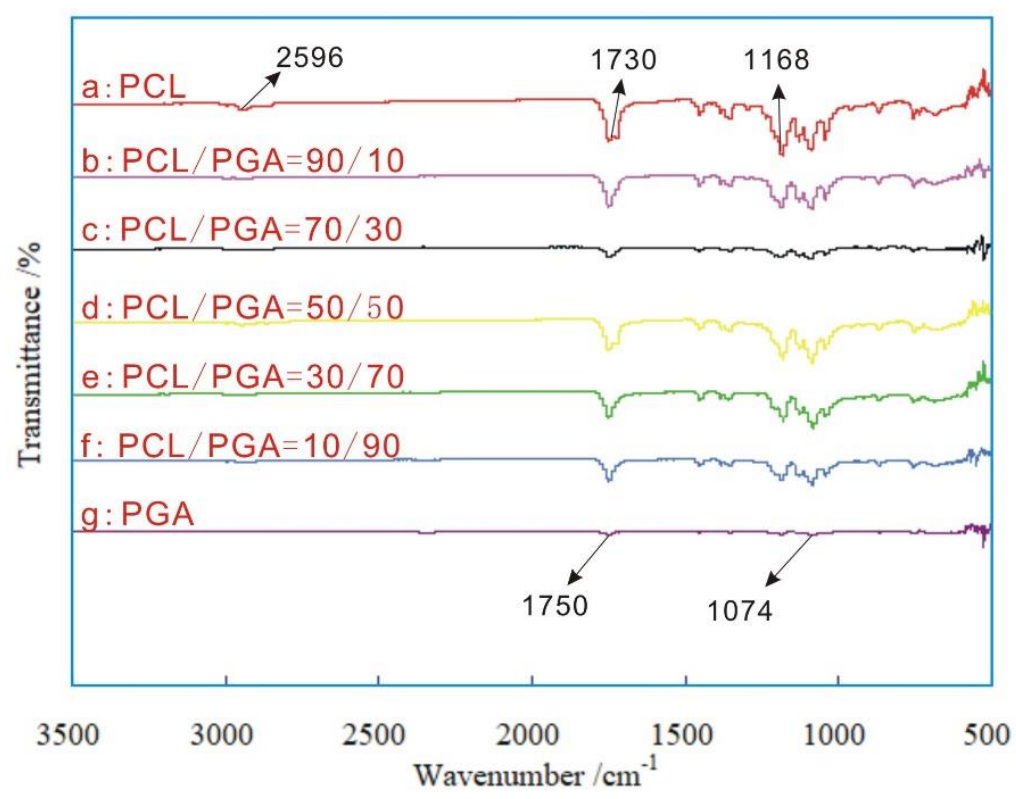

Figure 7. Infrared spectra of sutures coating with different proportions of PCL/PGA.

Figure 7a shows that the suture, coating with pure PCL, had many characteristic peaks, such as the asymmetric expansion vibration peak of $-\mathrm{C}-\mathrm{O}-\mathrm{C}$ at $1168 \mathrm{~cm}^{-1}$, the expansion vibration peak of $-\mathrm{C}=\mathrm{O}$ at $1730 \mathrm{~cm}^{-1}$ and the expansion vibration peak of $-\mathrm{CH}$ at $2956 \mathrm{~cm}^{-1}$. Figure $7 \mathrm{~g}$ shows the suture, coating with pure PGA, had many characteristic peaks, such as the bending vibration peak of $-\mathrm{CH}_{2}$ at $1074 \mathrm{~cm}^{-1}$ and the stretching vibration peak of $-\mathrm{C}=\mathrm{O}$ at $1752 \mathrm{~cm}^{-1}$. The sutures, coating with mixed PCL/PGA in 90/10, 70/30, 50/50, 30/70 and 10/90 as shown in Figure 7b-f, contained the characteristic peaks of PGA and PCL, which did not shift, and did not appear new peaks obviously. This indicated that these materials, such as the PLA suture, the PCL/PGA carriers and the CPFX drug, were just physically mixed rather than chemically reacted. This did not change the chemical structure of the CPFX drug, which was very useful for ensuring the original efficacy of CPFX drug.

\subsection{Mechanical Properties of Drug-Loaded PLA Suture}

The drug-PCL/PGA was coated on the surface of PLA suture, and the proportion of PCL/PGA was an important factor which affected the mechanical properties of suture, as shown in Figure 8.

Figure 8 shows that with the increasing of PCL in the carriers, the breaking strength and the breaking elongation of suture both increased. This is because the mechanical property of pure PCL was more excellent than that of pure PGA, therefore, with the increase of PCL in the carriers, both the breaking strength and the breaking elongation gradually improved. 


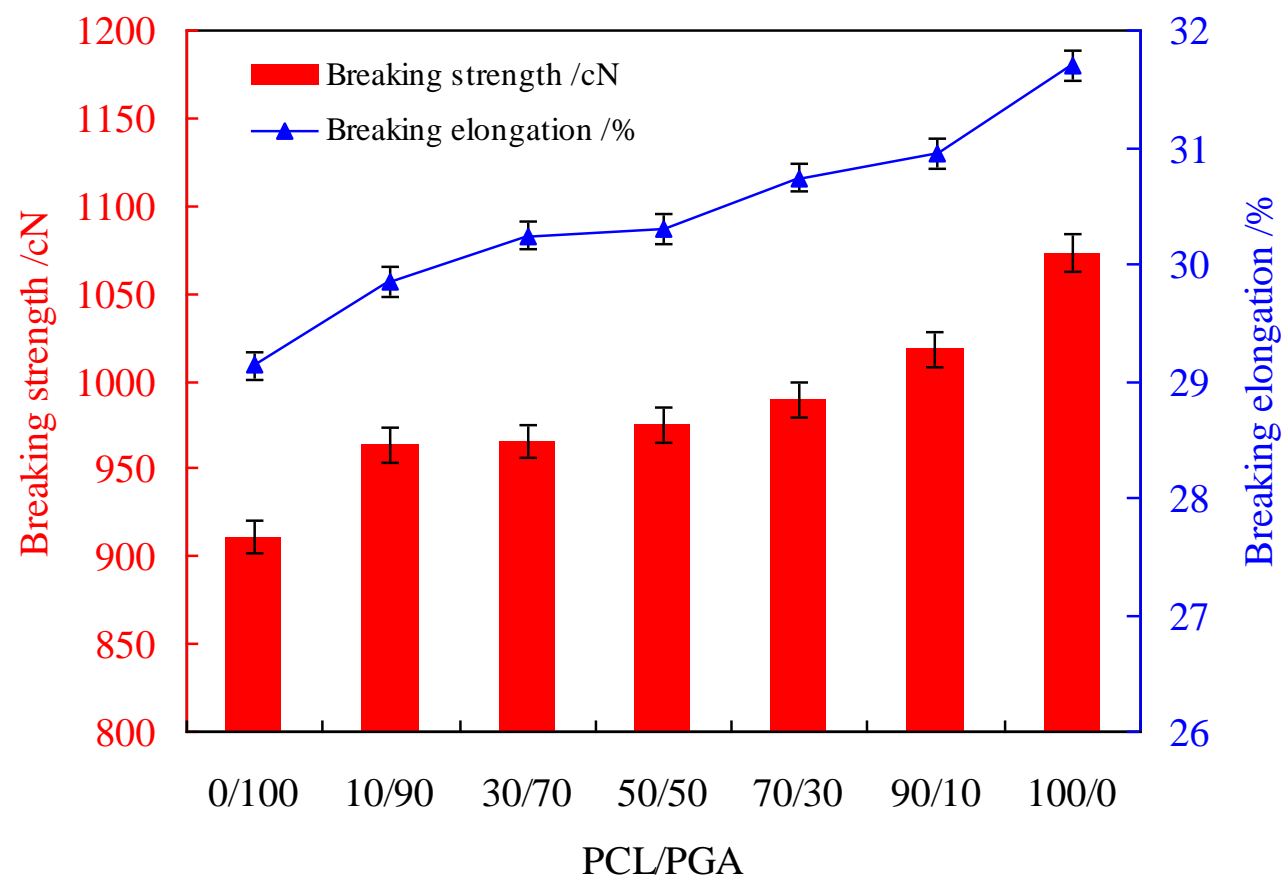

Figure 8. The breaking strength and elongation of the sutures coating with different proportions of PCL/PGA.

During the degradation process of sutures, the breaking strength of sutures, coating with different proportions of PCL/PGA, was changed, as shown in Figure 9.

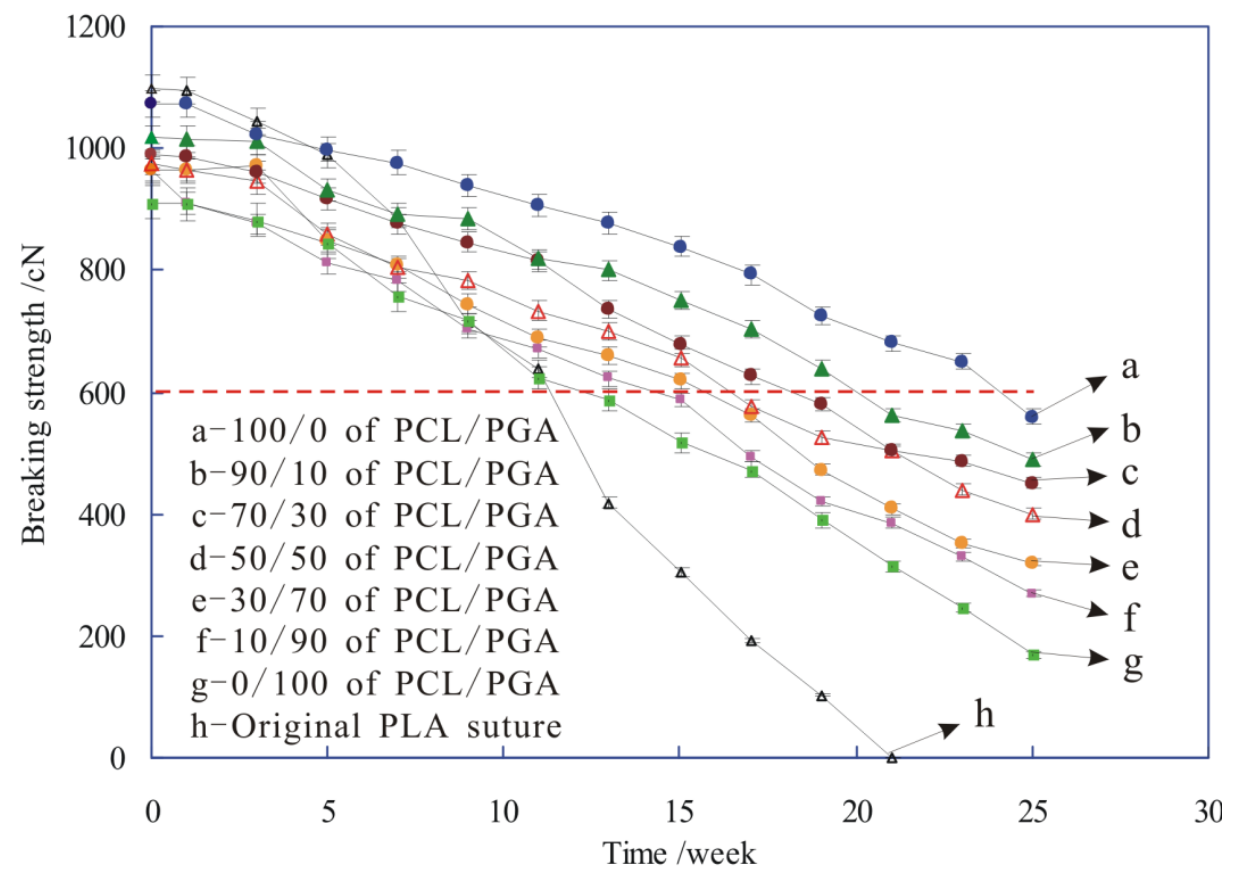

Figure 9. The breaking strength of sutures during degradation.

Figure 9 shows that at 0 weeks, the breaking strength of original PLA suture (h) was larger than that of these sutures coated with PCL/PGA $(\mathrm{a}-\mathrm{g})$, which is because that the original PLA suture was damaged by the solvent erosion or the mechanical action during the pretreatment and dip-padding process, and then the breaking strength of sutures reduced. 
It is also shown from Figure 9 that in the process of degradation with the prolonging of time, the breaking strength of all sutures $(\mathrm{a}-\mathrm{h})$ gradually decreased, and the strength reduction rate of original PLA was faster than that of the sutures coated with drug-PCL/PGA, which indicated that the degradation rate of original PLA suture (h) was much faster than that of other sutures $(\mathrm{a}-\mathrm{g})$. This is because with the gradual degradation of sutures, the structure of sutures was destroyed, and then their breaking strength decreased inevitably. Moreover, the suture gradually degraded from the coating materials to the inside fibers, and the coating materials of drug-PCL/PGA took some time to degrade, which caused that the structure of original PLA suture without any coating materials would damage more severely than that of these sutures coating with drug-PCL/PGA. Therefore, the degradation rate of original PLA suture was much faster than that of other sutures. Figure 5 also provides evidences to support this perspective.

In addition, when the breaking strength of sutures falls to a certain extent, the suture was broken under the wound tissue tension, and then lost its effect of tightening the wound. Therefore, in order to maintain the effectiveness of tightening wound, the strength of suture should be stronger than the certain standard of strength. For instance, the strength of skin injury suture is generally required more than $600 \mathrm{cN}$, so the $600 \mathrm{cN}$ is the standard of strength (red dotted line in Figure 9). The corresponding time of intersections between red dotted line and other strength lines are the effective strength-time of tightening wound for the suture, as shown in Table 1, which indicated that with the increase of PCL in the coating, the effective strength-time increased.

Table 1. The effective strength-time of tightening wound for the sutures.

\begin{tabular}{ccccccccc}
\hline PCL/PGA & $\begin{array}{c}\text { Original PLA } \\
\text { Suture }\end{array}$ & $\mathbf{0 / 1 0 0}$ & $\mathbf{1 0 / 9 0}$ & $\mathbf{3 0 / 7 0}$ & $\mathbf{5 0 / 5 0}$ & $\mathbf{7 0 / 3 0}$ & $\mathbf{9 0 / 1 0}$ & $\mathbf{1 0 0 / 0}$ \\
\hline $\begin{array}{c}\text { Effective strength-time } \\
\text { /weeks }\end{array}$ & 11.3 & 12.6 & 14.5 & 15.8 & 16.6 & 18.4 & 20.1 & 24.2 \\
\hline
\end{tabular}

\subsection{Drug-Release Behavior of Drug-Loaded PLA Suture}

The drug carrier of PCL/PGA, as the main coating material for the suture, was degraded gradually in the process of suture degradation. Meanwhile, the drug of ciprofloxacin (CPFX), which was carried by the PCL/PGA, was released from the carrier. The accumulated rate of drug-release was applied to evaluate the drug-release behavior of drug-loaded PLA suture, as shown in Figure 10.

Figure 10 shows that the drug-release rate of all sutures was very fast at the initial stage of degradation (within $100 \mathrm{~h}$ ), and then after $100 \mathrm{~h}$, the drug-release rate of sutures slowed down. Because the suture contained a lot of CPFX drug in the early stage of releasing, the drug of CPFX was very easy to release from the PCL/PGA carrier. As a result, the drug-release rate of sutures was very fast in the early stage (within $100 \mathrm{~h}$ ). In the later stage (after $100 \mathrm{~h}$ ), with the slow degradation of PCL/PGA carrier, the drug was released slowly from the drug-carrier of PCL/PGA.

Figure 10 also shows that the more PCL in the drug-carrier, the smaller accumulated rate of drug-release, which means a lower rate of drug releasing for the suture. This is because that the degradation rate of PCL was lower than that of PGA. Therefore, with the increasing of PCL in the drug-carrier, both the degradation rate and the drug-release rate reduced.

Different drug-release models were used to characterize the release mechanism of drugs [24-26]. The drug-release behavior was fitted by several classical drug release models, such as zero order model: $Q_{\mathrm{t}}=K t$, first-order drug release model: $\ln \left(1-Q_{\mathrm{t}}\right)=-K t$, Higuchi model: $Q_{t}=K t^{1 / 2}$, Ritger-Peppas model: $Q_{t}=K t^{\mathrm{n}}$, Hixon-Crowell model: $\left(1-Q_{t}\right)^{1 / 3}=K t$, Weibull distribution curve [27-29]. The data obtained from the release of ciprofloxacin in the buffer solution were simulated in this experiment. It is found that the release curve of CPFX in Figure 10 conforms to the Ritger-Peppas model of $Q_{t}=K t^{\mathrm{n}}$, as shown in Table 2. 


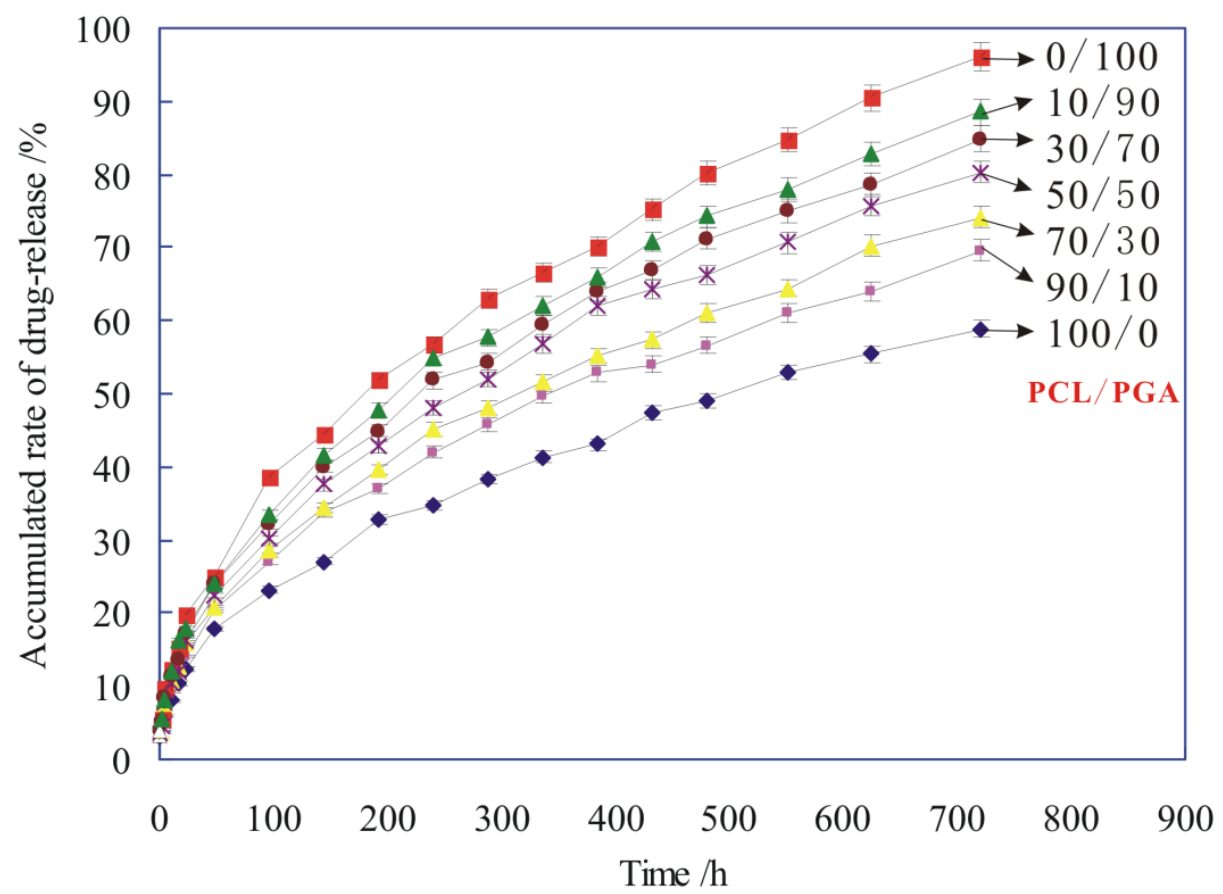

Figure 10. The accumulated rate of drug-release of sutures with different proportions of PCL/ PGA carriers.

Table 2. Fitting parameters of drug release Ritger-Peppas model of $Q_{t}=K t^{\mathrm{n}}$.

\begin{tabular}{ccccccccc}
\hline PCL/ PGA & & $\mathbf{1 0 0 / 0}$ & $\mathbf{9 0 / 1 0}$ & $\mathbf{3 0 / 7 0}$ & $\mathbf{5 0 / 5 0}$ & $\mathbf{3 0 / 7 0}$ & $\mathbf{1 0 / 9 0}$ & $\mathbf{0 / 1 0 0}$ \\
\hline Ritger-Peppas & $K$ & 2.7829 & 3.3780 & 3.4313 & 4.1898 & 3.4539 & 3.1845 & 4.0301 \\
Equation: & $n$ & 0.4644 & 0.4587 & 0.4665 & 0.4765 & 0.4797 & 0.4718 & 0.4703 \\
$Q_{t}=K t^{n}$ & $R^{2}$ & 0.9992 & 0.9993 & 0.9994 & 0.9994 & 0.9993 & 0.9996 & 0.9994 \\
\hline
\end{tabular}

According to some literatures [30,31], the mechanism of drug-release was drug diffusion, when $n \leq 0.45$. When $0.45<n<0.89$, the drug diffusion and the dissolution of drug carrier have a synergistic effect on the release rate of drug. The drug release fits with the skeleton dissolution mechanism when $n \geq 0.89$. It can be seen from Table 2 that the value of " $n$ " is between 0.45 and 0.89 , so the drug release mechanism of CPFX-PCL/PGA, in this paper, is a synergistic effect of drug diffusion and PCL/PGA carrier dissolution.

\section{Conclusions}

The fibers in original PLA suture were very loose, and its surface was very smooth. The surface of the PLA suture, coating with PCL/PGA, was very rough, which led to increased stitching resistance. In the process of degradation, the suture gradually degraded from the coating materials to the inside fibers. With the increasing of PCL in the coating of suture, the degradation rate of the coating goes down. The infrared spectra of sutures shows that these coating materials were just physically mixed and did not form any new chemical bonds, which was very useful for ensuring the original efficacy of CPFX drug. With the increasing of PCL in the carriers, both the breaking strength and the breaking elongation of suture increased. The breaking strength of original PLA suture was larger than that of these sutures coated with PCL/PGA. During degradation, the breaking strength of all sutures gradually decreased, and the more PCL in the coating materials, the longer effective strength-time for the suture. The drug-release rate of all sutures was very fast at the initial stage of degradation (within $100 \mathrm{~h}$ ), and then the drug-release rate of sutures began to slow down (after $100 \mathrm{~h}$ ). With the increasing of PCL in the drug-carrier, the rate of drug releasing became lower. The drug release mechanism of CPFX-PCL/PGA, in this paper, was a synergistic effect of drug diffusion and PCL/PGA carrier dissolution. 
Author Contributions: Conceptualization, S.L. and G.W.; Methodology, S.L. and G.W.; Validation, J.Y., H.L., K.W. and B.W.; Formal Analysis, J.Y. and J.Y.; Investigation, J.Y., H.L. and B.W.; Resources, M.L., Y.Z., J.Z., J.W., Y.J., F.L., M.Z. and P.W.; Data Curation, Y.J.; Writing-Original Draft Preparation, J.Y.; Writing-Review \& Editing, S.L., G.W., F.L. and M.Z; Project Administration, S.L.; Funding Acquisition, S.L. and G.W. All authors have read and agreed to the published version of the manuscript.

Funding: This work was supported by the MOE (Ministry of Education in China) Project of Humanities and Social Sciences (No. 18YJC760051), 2017 Shanxi Philosophy and Social Science Project (No. 201702), Program for the Philosophy and Social Sciences Research of Higher Learning Institutions of Shanxi (PSSR) (No. 201803060) and the Scientific and Technological Innovation Programs of Higher Education Institutions in Shanxi, China (No. 2015125).

Conflicts of Interest: The authors declare no conflict of interest.

\section{References}

1. Valente, T.A.M.; Silva, D.M.; Gomes, P.S.; Fernandes, M.H.; Santos, J.D.; Sencadas, V. Effect of sterilization methods on electrospun poly(lactic acid) (PLA) fiber alignment for biomedical applications. Adv. Drug Deliver. Rev. 2016, 8, 3241-3249. [CrossRef] [PubMed]

2. Madhavan, N.K.; Nair, N.R.; John, R.P. An overview of the recent developments in polylactide (PLA) research. Bioresource Technol. 2010, 101, 8493-8501. [CrossRef] [PubMed]

3. Anderson, J.M.; Shive, M.S. Biodegradation and biocompatibility of PLA and PLGA microspheres. Adv. Drug Deliver. Rev. 2012, 64, 72-82. [CrossRef]

4. Schrumpf, M.A.; Lee, A.T.; Weiland, A.J. Foreign-body reaction and osteolysis induced by an intraosseous poly-L-lactic acid suture anchor in the wrist: Case report. J. Hand Surg. 2011, 36, 1769-1773. [CrossRef] [PubMed]

5. Nakano, Y.; Hori, Y.; Sato, A.; Watanabe, T.; Takada, S.; Goto, H.; Inagaki, A.; Ikada, Y.; Satomi, S. Evaluation of a poly(L-lactic acid) stent for sutureless vascular anastomosis. Ann. Vasc. Surg. 2009, 23, 231-238. [CrossRef] [PubMed]

6. Moy, R.L.; Kaufman, A.J. Clinical comparison of polyglactic acid (vicryl) and polytrimethylene carbonate (maxon) suture material. J. Dermatol. Surg. Oncol. 2013, 17, 667-669. [CrossRef]

7. Gaynes, R.P.; Culver, D.H.; Horan, T.C.; Edwards, J.R.; Richards, C.; Tolson, J.S. Surgical site infection (SSI) rates in the united states, 1992-1998: The national nosocomial infections surveillance system basic SSI risk index. Clin. Infect. Dis. 2001, 33, S69-S77. [CrossRef]

8. He, C.L.; Huang, Z.M.; Han, X.J. Fabrication of drug-loaded electrospun aligned fibrous threads for suture applications. J. Biomed. Mater. Res. A 2009, 89, 80-95. [CrossRef]

9. Asri, L.A.T.W.; Crismaru, M.; Roest, S.; Chen, Y.; Ivashenko, O.; Rudolf, P.; Tiller, J.C.; van der Mei, H.C.; Loontjens, T.J.A.; Busscher, H.J. A shape-adaptive, antibacterial-coating of immobilized quaternary-ammonium compounds tethered on hyperbranched polyurea and its mechanism of action. Adv. Funct. Mater. 2014, 24, 346-355. [CrossRef]

10. Varghese, N.M.; Venkatachalam, S.; Saxena, S.K. Nanocarriers for brain specific delivery of anti-retro viral drugs: Challenges and achievements. J. Drug Target. 2018, 26, 195-207. [CrossRef]

11. Lee, E.J.; Huh, B.K.; Kim, S.N.; Lee, J.Y.; Park, C.G.; Mikos, A.G.; Bin Choy, Y. Application of materials as medical devices with localized drug delivery capabilities for enhanced wound repair. Prog. Mater. Sci. 2017, 89, 392-410. [CrossRef] [PubMed]

12. Ahmad, Z.; Stride, E.; Edirisinghe, M. Novel preparation of transdermal drug-delivery patches and functional wound healing materials. J. Drug Target. 2009, 17, 724-729. [CrossRef] [PubMed]

13. Champeau, M.; Thomassin, J.M.; Tassaing, T.; Jerome, C. Drug loading of sutures by supercritical $\mathrm{CO}_{2}$ impregnation: Effect of polymer/ drug interactions and thermal transitions. Macromol. Mater. Eng. 2015, 300, 596-610. [CrossRef]

14. Lee, D.H.; Kwon, T.Y.; Kim, K.H.; Kwon, S.T.; Cho, D.H.; Jang, S.H.; Son, J.S.; Lee, K.B. Anti-inflammatory drug releasing absorbable surgical sutures using poly(lactic-co-glycolic acid) particle carriers. Polym. Bull. 2014, 71, 1933-1946. [CrossRef]

15. Weldon, C.B.; Tsui, J.H.; Shankarappa, S.A.; Nguyen, V.T.; Ma, M.L.; Anderson, D.G.; Kohane, D.S. Electrospun drug-eluting sutures for local anesthesia. J. Control. Release 2012, 161, 903-909. [CrossRef] [PubMed] 
16. Toosi, S.; Naderi-Meshkin, H.; Kalalinia, F.; Peivandi, M.T.; HosseinKhani, H.; Bahrami, A.R.; Heirani-Tabasi, A.; Mirahmadi, M.; Behravan, J. PGA-incorporated collagen: Toward a biodegradable composite scaffold for bone-tissue engineering. J. Biomed. Mater. Res. A 2016, 104, 2020-2028. [CrossRef] [PubMed]

17. Surucu, S.; Sasmazel, H.T. Development of core-shell coaxially electrospun composite PCL/chitosan scaffolds. Int. J. Biol. Macromol. 2016, 92, 321-328. [CrossRef]

18. Liu, S.Q.; Wu, G.H.; Chen, X.G.; Zhang, X.F.; Yu, J.J.; Liu, M.F.; Zhang, Y.; Wang, P. Degradation behavior in vitro of carbon nanotubes (CNTs) /poly(lactic acid) (PLA) composite suture. Polymers 2019, 11, 01015. [CrossRef]

19. Alonso, J.J.S.; El Kori, N.; Melian-Martel, N.; Del Rio-Gamero, B. Removal of ciprofloxacin from seawater by reverse osmosis. J. Environ. Manag. 2018, 217, 337-345. [CrossRef]

20. Sun, B.; Li, D.; Linghu, W.S.; Guan, X.H. Degradation of ciprofloxacin by manganese(III) intermediate: Insight into the potential application of permanganate/ bisulfite process. Chem. Eng. J. 2018, 339, 144-152. [CrossRef]

21. Gonzalez, J.A.; Bafico, J.G.; Villanueva, M.E.; Giorgieri, S.A.; Copello, G.J. Continuous flow adsorption of ciprofloxacin by using a nanostructured chitin/graphene oxide hybrid material. Carbohyd. Polym. 2018, 188, 213-220. [CrossRef] [PubMed]

22. Tamboli, V.; Mishra, G.P.; Mitra, A.K. Novel pentablock copolymer (PLA-PCL-PEG-PCL-PLA)-based nanoparticles for controlled drug delivery: Effect of copolymer compositions on the crystallinity of copolymers and in vitro drug release profile from nanoparticles. Colloid Polym. Sci. 2013, 291, 1235-1245. [CrossRef] [PubMed]

23. Zheng, X.Y.; Li, H.L.; He, Y.; Yuan, M.W.; Shen, M.L.; Yang, R.Y.; Jiang, N.F.; Yuan, M.L.; Yang, C. Preparation and in vitro release of total alkaloids from alstonia scholaris leaves loaded mPEG-PLA microspheres. Materials 2019, 12, 1457. [CrossRef] [PubMed]

24. D'Souza, A.J.M.; Schowen, R.L.; Topp, E.M. Polyvinylpyrrolidone-drug conjugate: Synthesis and release mechanism. J. Control. Release 2004, 94, 91-100. [CrossRef] [PubMed]

25. Kim, H.; Fassihi, R. Application of a binary polymer system in drug release rate modulation. 1. characterization of release mechanism. J. Pharm. Sci. 1997, 86, 316-322. [CrossRef]

26. Park, E.S.; Maniar, M.; Shah, J.C. Biodegradable polyanhydride devices of cefazolin sodium, bupivacaine, and taxol for local drug delivery: Preparation, and kinetics and mechanism of in vitro release. J. Control. Release 1998, 52, 179-189. [CrossRef]

27. Chessa, S.; Huatan, H.; Levina, M.; Mehta, R.Y.; Ferrizzi, D.; Rajabi-Siahboomi, A.R. Application of the dynamic gastric model to evaluate the effect of food on the drug release characteristics of a hydrophilic matrix formulation. Int. J. Pharm. 2014, 466, 359-367. [CrossRef]

28. Donbrow, M.; Friedman, M. Timed release from polymeric films containing drugs and kinetics of drug release. J. Pharm. Sci. 2010, 64, 76-80. [CrossRef]

29. Lindstrom, F.T.; Ayres, J.W. Diffusion model for drug release from suspensions II: Release to a perfect sink. J. Pharm. Sci. 2010, 66, 662-668. [CrossRef]

30. Vachon, M.G.; Nairn, J.G. Physico-chemical evaluation of acetylsalicylic acid-eudragit RS100 microspheres prepared using a solvent-partition method. J. Microencapsul. 1995, 12, 287-305. [CrossRef]

31. Wei, W.; Shi, S.J.; Liu, J.; Sun, X.; Ren, K.; Zhao, D.; Zhang, X.N.; Zhang, Z.R.; Gong, T. Lipid nanoparticles loaded with 10- hydroxycamptothecin -phospholipid complex developed for the treatment of hepatoma in clinical application. J. Drug Target. 2010, 18, 557-566. [CrossRef] [PubMed]

(C) 2020 by the authors. Licensee MDPI, Basel, Switzerland. This article is an open access article distributed under the terms and conditions of the Creative Commons Attribution (CC BY) license (http://creativecommons.org/licenses/by/4.0/). 